\title{
Nanocellulose production in future biorefineries: an integrated approach using tailor-made enzymes
}

\author{
Paula Squinca ${ }^{\dagger, t}$, Stanley Bilatto ${ }^{\dagger}$, Alberto C. Badino ${ }^{\ddagger}$, Cristiane S. Farinas ${ }^{\dagger, t}, *$ \\ ${ }^{\dagger}$ Nanotechnology National Laboratory for Agriculture (LNNA), Embrapa \\ Instrumentation, Rua XV de Novembro 1452, 13560-970, São Carlos, SP, Brazil
}

*Graduate Program of Chemical Engineering, Federal University of São Carlos, Rod. Washington Luiz, km 235, 13565-905, São Carlos, SP, Brazil

Corresponding author

E-mail address: cristiane.farinas@embrapa.br

Tel.: +55-16-2107-2908

Fax: +55-16-2107-5754

Number of Pages: 6

Number of Figures: 2

Number of Tables: 0 


\section{Supporting Information}

(6 pages and 2 figures)

Figure S1. FE-SEM images of the nanocelluloses obtained from a) run 1, c)

run 2, e) run $3, \mathrm{~g}$ ) run 4 , i) run $5, \mathrm{k}$ ) run $6, \mathrm{~m}$ ) run 7, o) run 8, q) run 9 using 48

h of hydrolysis and from b) run 1 , d) run 2, f) run 3, h) run 4 , j) run 5 , I) run 6 ,

n) run $7, p$ ) run 8 and r) run 9 using $96 \mathrm{~h}$ of hydrolysis. FE-SEM images of

suspensions obtained from s) run 12 and t) run 13 (without enzymes).
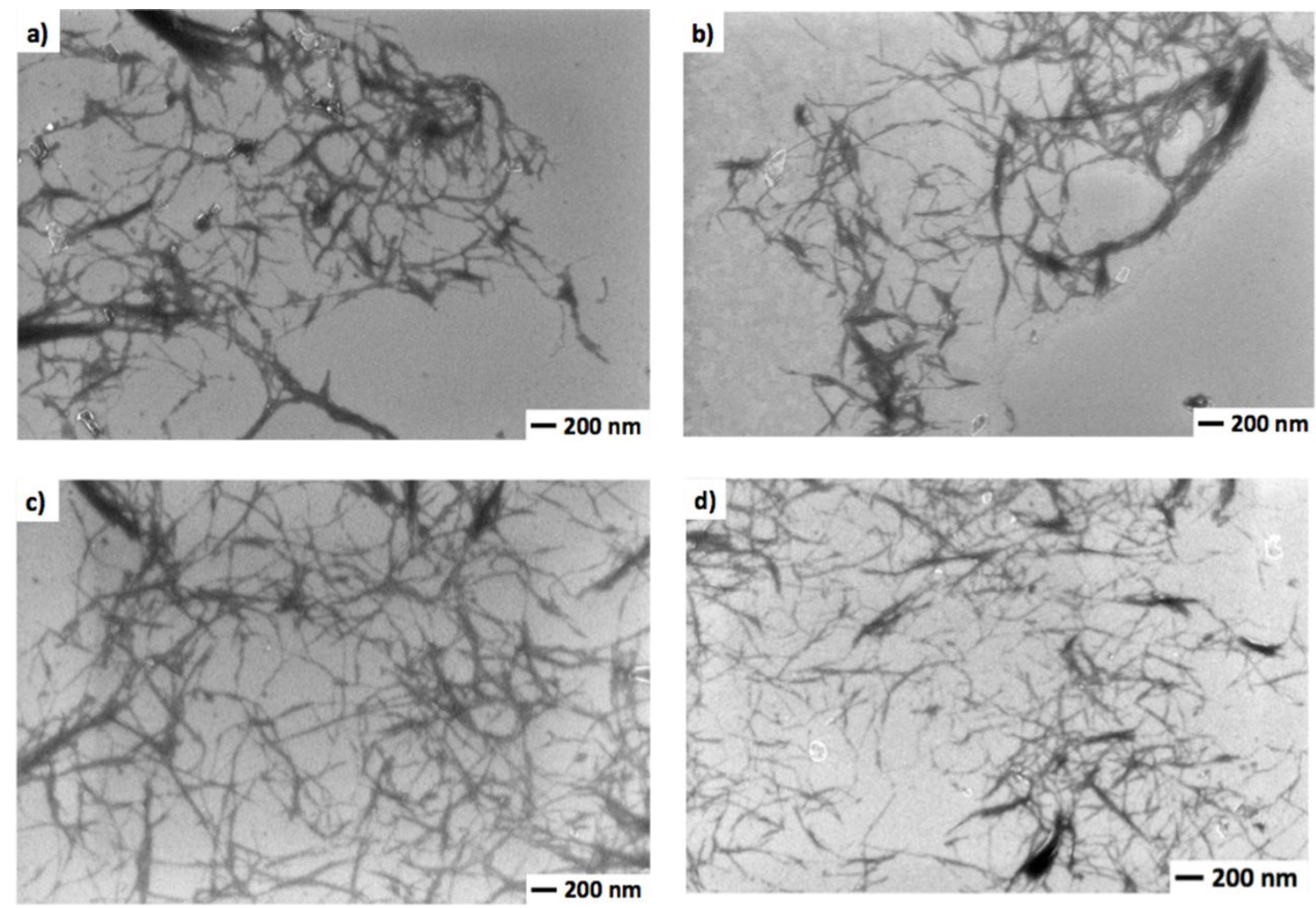

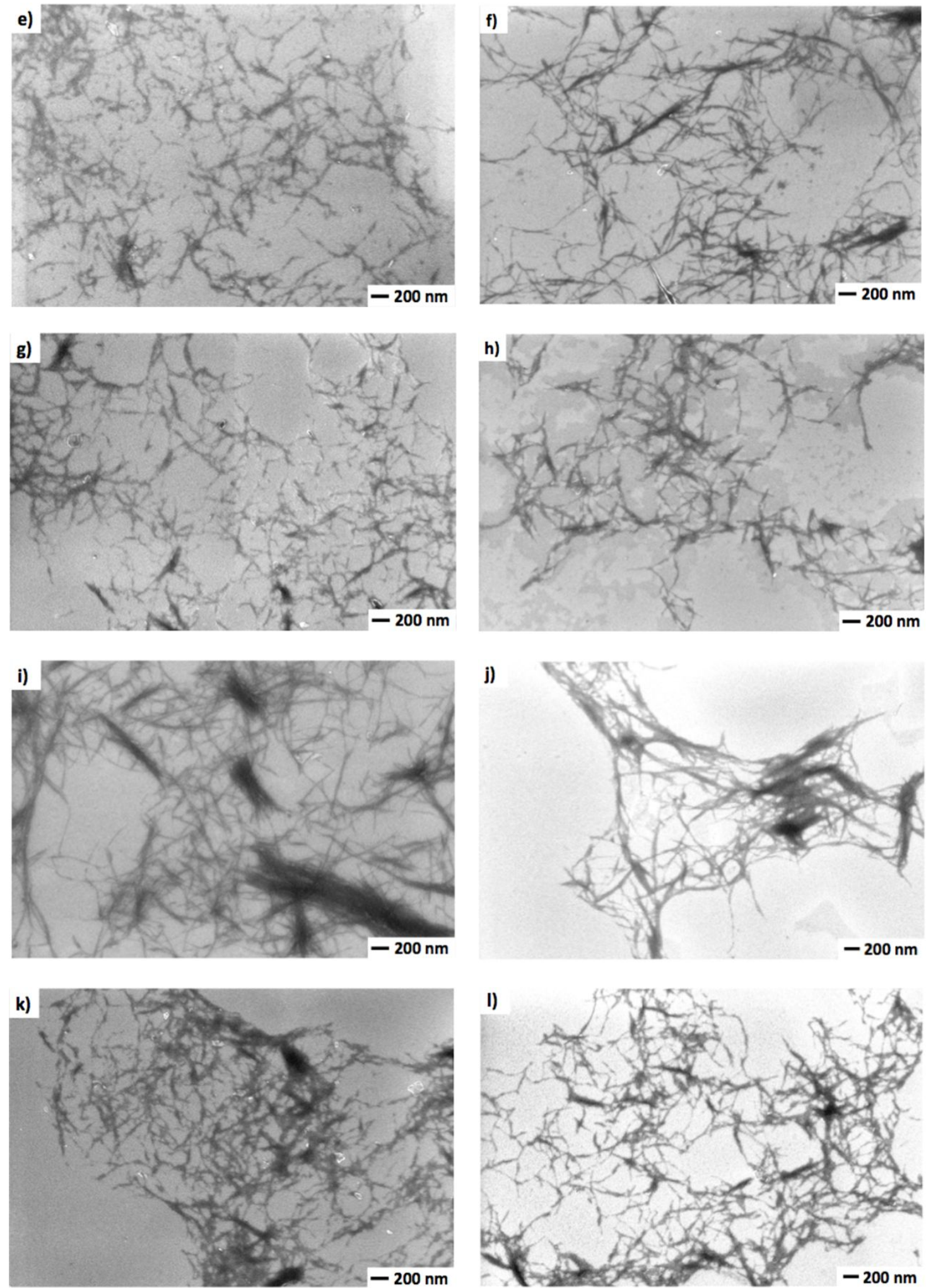

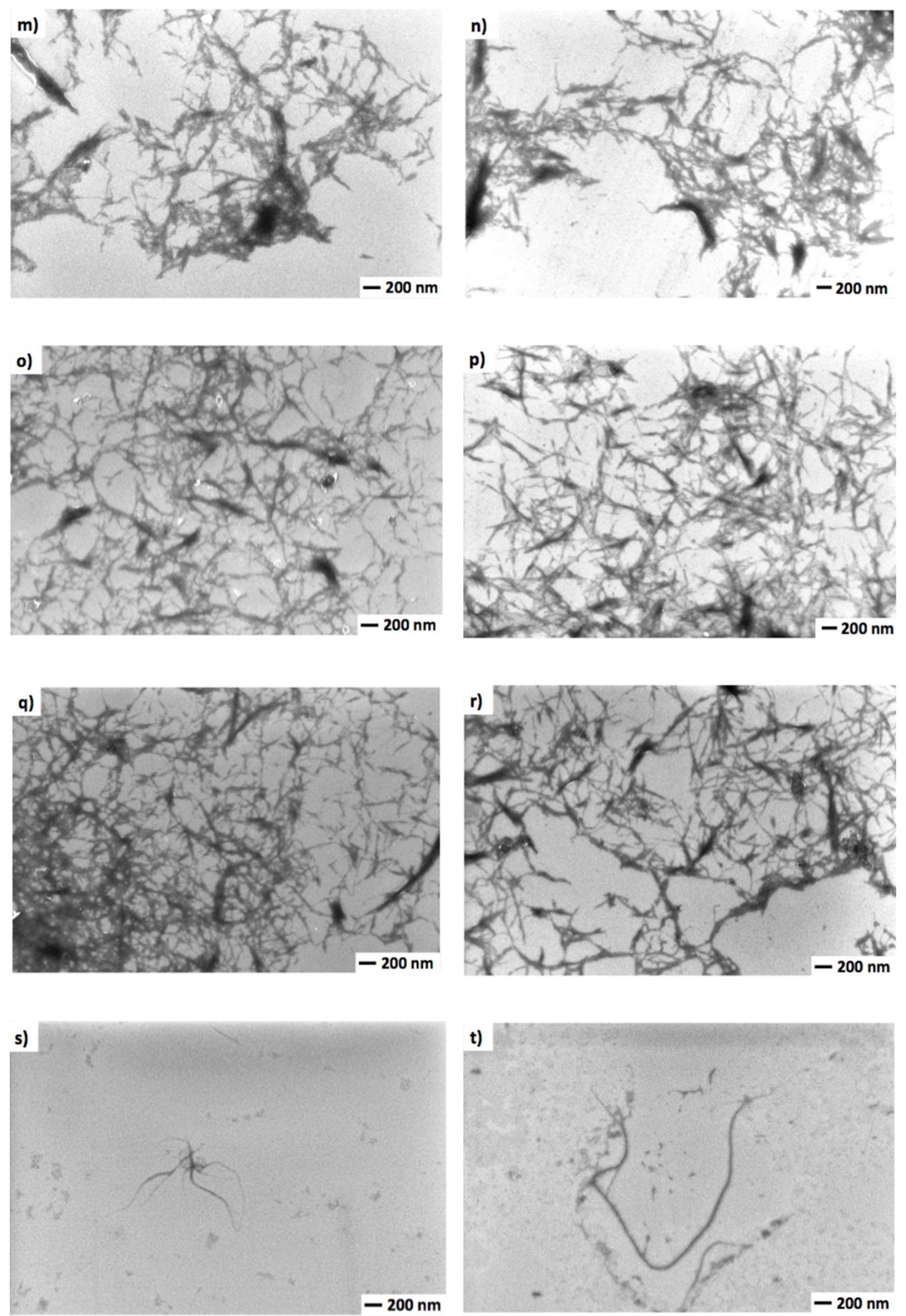


\section{XRD}

The crystallinities of the original precursor, the material after different times of ball milling, and the CNCs were investigated by X-ray diffraction. All the diffractograms presented defined crystalline peaks, showing the same cellulose I characteristic peaks at $2 \theta$ angles of around $16^{\circ}$ (overlapped (110) and (110) planes), $22.5^{\circ}$ ((200) plane), and $35^{\circ}$ ((004) plane).

The crystallinity varied depending on the mechanical treatments applied. The influence of ball milling on the precursor material is shown in the diffractogram of Figure S2a.

There was clear peak broadening as the ball milling time was increased, resulting in decreases of the fiber crystallinity index values of up to $31 \%$ (for $90 \mathrm{~min}$ of ball milling), which could be attributed to partial destruction of the crystalline structure, resulting in more disordered regions in the cellulose fiber.

After the hydrolysis (Figure S2b,c):, the peak at $2 \theta$ of $22.5^{\circ}$ became sharper, due to increased crystallinity of the CNCs after the removal of amorphous components. The diffractograms also showed a clear influence of the absence of enzymes, which resulted in lower crystallinity indexes. 
Figure S2. X-ray diffractograms of a) the eucalyptus cellulose pulp and b) and c) the nanocelluloses obtained under the different CCRD conditions. 

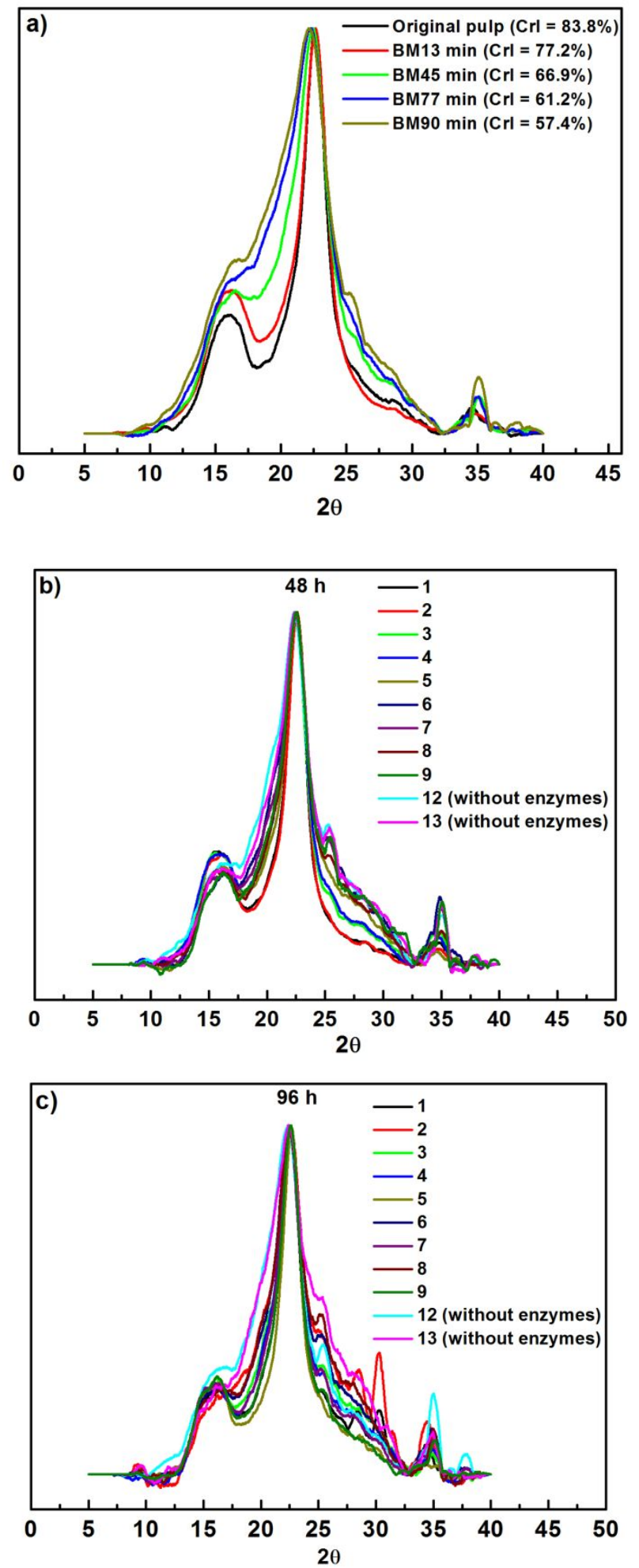